This is a pre-print submitted to EarthArXiv and has not been peer reviewed

\title{
ICESat-2 Reservoir Applications: A case study from the largest man-made reservoir in India
}

\author{
Surajit Ghosh ${ }^{1}$, Atul Kaushik ${ }^{2}$ \\ ${ }^{1}$ International Water Management Institute, Colombo, Sri Lanka \\ ${ }^{2}$ National Institute of Advanced Studies, India
}

Corresponding Email: surajitghosh@gmail.com

\begin{abstract}
Monitoring inland water levels is crucial for understanding hydrological processes to climate change impact leading to policy implementation. Satellite altimetry has proved to be an excellent technique to precisely measure water levels of rivers, lakes, and other inland water bodies. The ATL13 product of ICESat- 2 spaceborne LiDAR is solely dedicated to inland water bodies. The water surface heights were derived from ICESat-2's strong beams, and performance was assessed with respect to reservoir gauge observations. Statistical measurements were used to understand the agreement $\left(\mathrm{R}^{2}=0.99, \% \mathrm{RMSE}=0.08\right)$ among the datasets. An $\mathrm{R}^{2}$ value of 0.99 was observed between ICESat- 2 derived water level anomaly and the reservoir storage anomaly. This study provides a unique opportunity to utilize the ATL13 data product to study reservoir water level variation and estimate the reservoir's storage. The methodology can also be helpful to understand the reservoir storage variation in a data-sparse region.
\end{abstract}

Keywords- ICESat-2, ATL13, reservoir water level, reservoir storage capacity

\section{Scientific Correspondence}

In the present global scenario, increasing demand for food grains, the uncertainty of rainfall, lowering of groundwater table, less availability of groundwater etc., have increased the dependency of cultivation on canal irrigation that is mainly supplied from reservoirs. Thus, water management for agriculture is related to water resources management, food production, rural development, and other natural resources management. Reservoirs are constructed for multi-purpose usage, including irrigation, hydropower, flood control and soil erosion reduction in the downstream areas. Continuous long-term monitoring of the inland waterbodies (in terms of water level, surface area, storage and discharge) can add vital knowledge to comprehend the cause and effect of climate change and anthropogenic activities.

The spatial coverage of in-situ stations is uneven and not sufficient globally for various reasons ${ }^{1}$. In addition, the gauges that are present are often not tied to a standard vertical datum. On the other hand, satellite altimetry, both radar and LiDAR, offers an opportunity to monitor inland water levels ${ }^{2}$. Compared to radar altimeters, laser altimeters are characterized by small footprints and high-density samplings. The

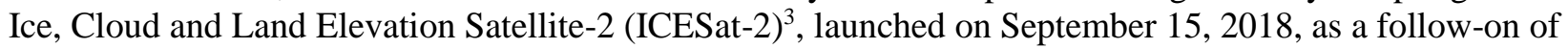
the ICESat mission, has enormous potential to do research on inland waters. However, the performance of ICESat-2 over the inland waters is not reported much globally as well as in the Indian context. ICESat-2 has six laser beams with a wavelength of $532 \mathrm{~nm}$. Each beam has a circular footprint with a nominal diameter of $\sim 14 \mathrm{~m}$, and the footprints on the ground are spaced $\sim 0.7 \mathrm{~m}$ along-track, thus having a high degree of overlap. The ATL13 data is available in the form of segments, with each segment reporting information collected from 100 signal photons ${ }^{4}$. The ATL13 dataset provides along-track heights for lakes, rivers, and wetlands with reference to the EGM2008. Along with the height product, quality control fields are also provided.

The present study uses ATL13 data over Govind Ballabh Pant Sagar Dam (also known as Rihand dam located in Uttar Pradesh State, India) to assess the utility of ICESat-2 in reservoir water level and storage studies. The Govind Ballabh Pant Sagar is India's largest artificial reservoir and the largest dam of India by volume. It is on the river Rihand the main tributary of Son (Tributary of Ganga river). The 
catchment area of the Rihand dam covers areas over Uttar Pradesh, Madhya Pradesh \& Chhattisgarh, and it supplies irrigation water to Bihar state located downstream of the river. The water stored in Rihand Dam is released into the River Son periodically for irrigation purposes throughout the year. First, ICESat2/ATL13 segments were utilized within the reservoir boundary (Figure 1). Second, cloud flags were used to get the best measure. Finally, the water surface heights between the $5^{\text {th }}$ percentile and $95^{\text {th }}$ percentile for each observation date were considered to avoid extreme values. The water level time series datasets were further constructed using median values to get the optimum water level from various segments of a single date. All the data extraction and filtering steps were carried out in the R environment. ICESat- 2 derived the water level time series datasets were compared with the gauge station. In-situ water level and storage datasets were collected from the India WRIS platform.

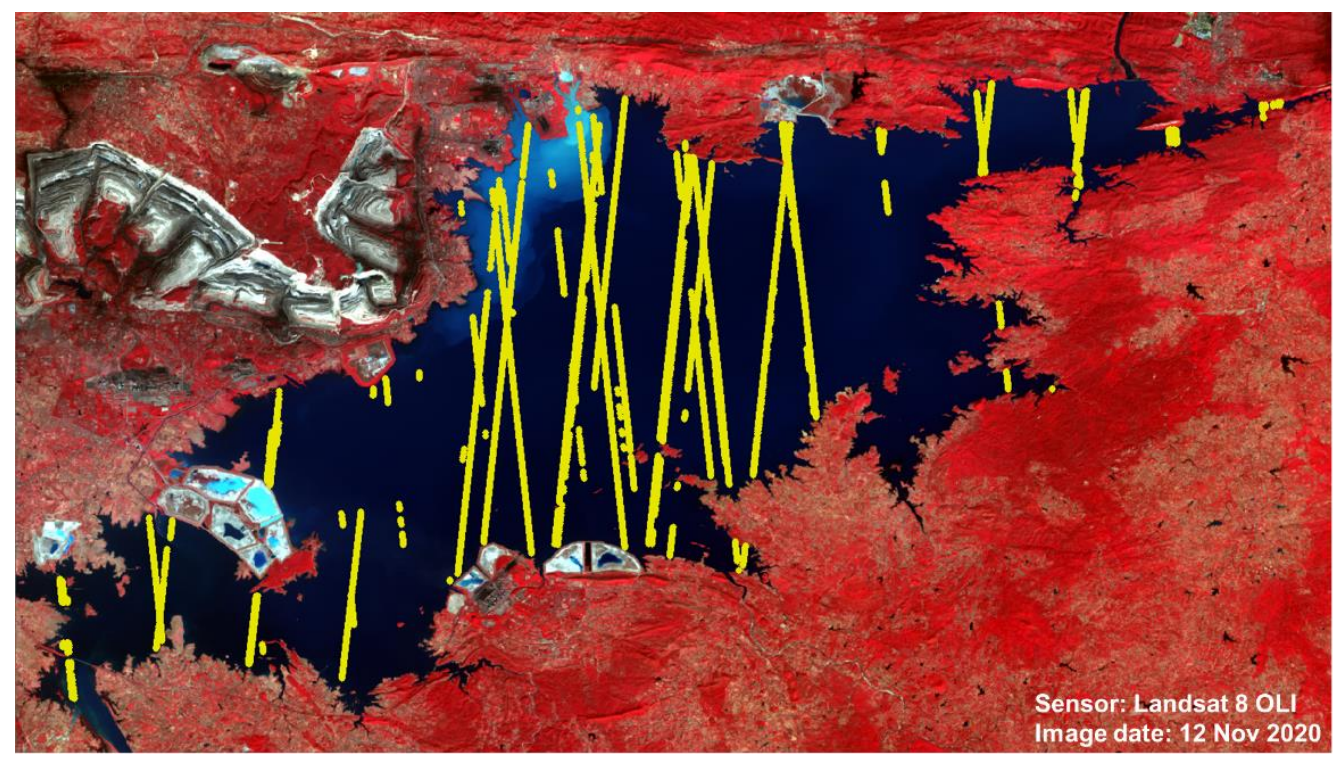

Figure 1 Govind Ballabh Pant Sagar with ICESat-2/ATL13 segments (yellow colour dots) 


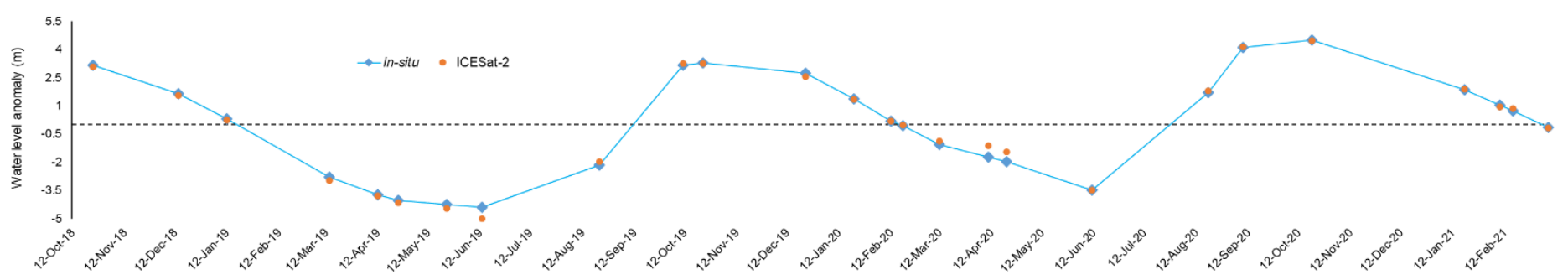

Figure 2 Water level anomaly time series

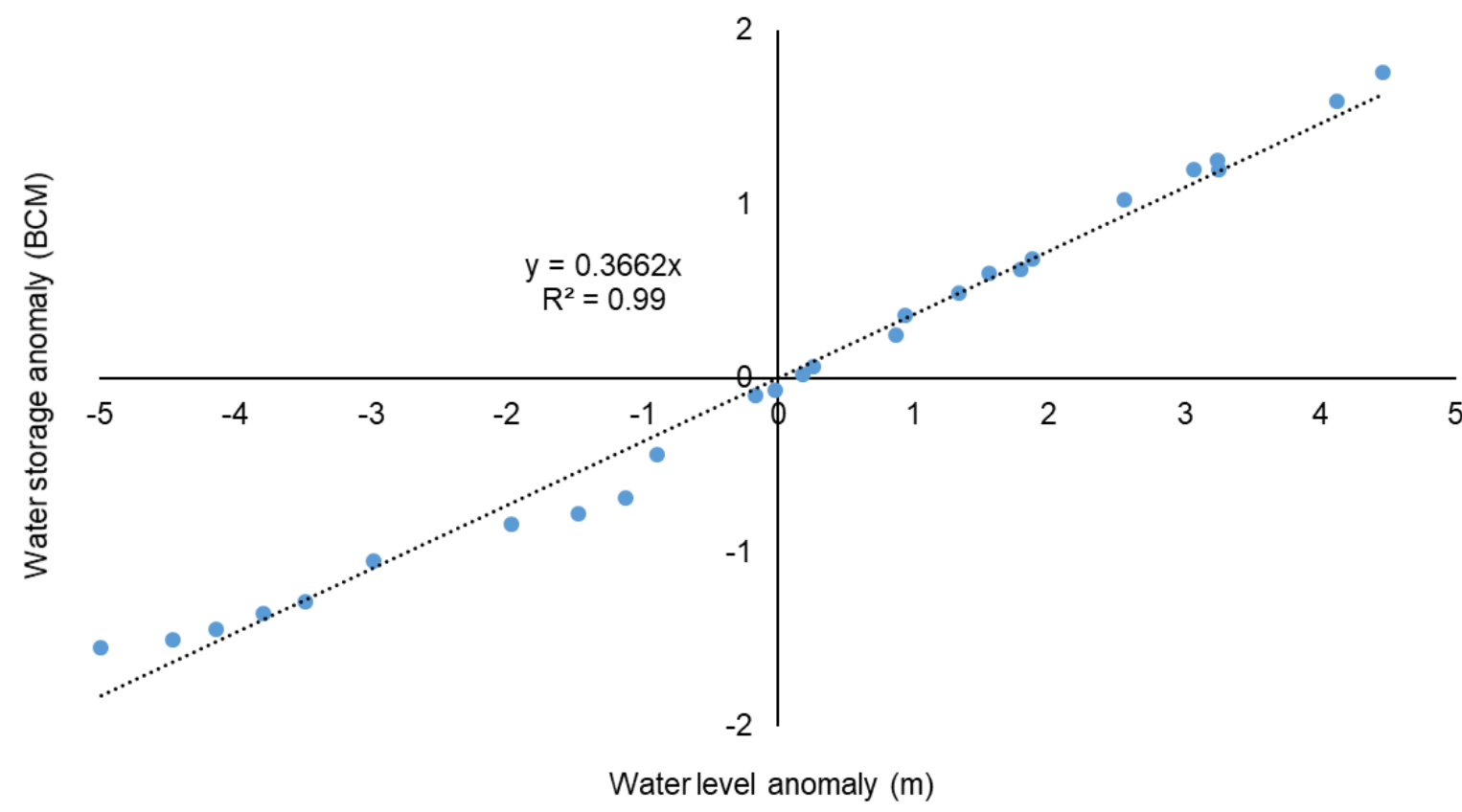

Figure 3 ICESat-2/ATL13 derived Water level anomaly vs reservoir Storage anomaly

The proposed methodology aims to provide a framework for monitoring reservoir water levels. Further, using this framework, users can also verify the accuracy of ATL13 products wherever gauge station data is available and can also estimate storage of reservoir corresponding to ATL13 water level height. The present study calculated water level and storage anomalies to compare the datasets. The time series of reservoir water level anomalies for both ICESat-2 observations as well as in-situ gauge observations are shown in Figure 2. There is an excellent agreement between the two datasets, further reflected by $\mathrm{R}^{2}$ and $\%$ RMSE values of 0.99 and 0.08, respectively. Figure 3 shows the relationship between ICESat- 2 derived water level anomaly and the in-situ reservoir water storage anomaly. An $\mathrm{R}^{2}$ value of 0.99 was observed between the two sets of observations. It indicates that ICESat- 2 observations have great potential to predict the water storage capacity of the reservoir, in the case when the in-situ observations are not available due to operational issues or gauge is altogether absent at the reservoir, specially in remote regions. 


\section{This is a pre-print submitted to EarthArXiv and has not been peer reviewed}

The conventional approach for calculating reservoir volume often used the reservoir's absolute water level and underwater topography obtained through the rigorous bathymetric survey. However, the regular hydrographic survey is time-consuming, expensive and tedious. Therefore, periodic evaluation of reservoir storage capacity is neglected under the data-limited situation. The satellite altimetry ensures and facilitates the continuous monitoring of the surface water at near-global coverage in near real-time, which is very much helpful for data-sparse basins ${ }^{5}$. CWC's Weekly Reservoir Storage Bulletins include 133 reservoirs, where the country has more than three thousand reservoirs. As a result, the water storage situation in India excludes a large number of reservoirs. On the other hand, there is a strong linkage between agricultural water availability and reservoir water storage. The agricultural water availability in India during droughts has been a critical issue. Thus reservoir storage is a decisive indicator to predict agricultural drought downstream. It is clear that we certainly need to improve the water storage monitoring system, and satellite altimetry can play a crucial role in this regard. Remote sensing products are progressively being integrated with monitoring and early warning systems at the national and regional levels. ICESat-2 can provide water level information where in-situ data are limited/scarce/unreliable. The present study extracted time series water levels from the ICESat-2 ATL13 product. The study provides unique insight for studying reservoir water level and storage using ATL13 data in the R environment ${ }^{6}$. The presented framework can also complement the forthcoming Surface Water Ocean Topography (SWOT) mission by directly measuring the surface water (lakes, reservoirs, rivers, and wetlands) component of the water cycle, which will help provide additional inputs for monitoring surface water storage. Since all the datasets are open source, any researcher or concerned authorities can implement the proposed framework with limited resources for any region where satellite tracks are available without any dependency. Thus, the proposed framework provides an opportunity to monitor one of the crucial hydrological parameters like reservoir water level/storage, which can be integrated with other altimetry sensors to increase the spatiotemporal observations.

\section{References}

1. Lawford, R., Strauch, A., Toll, D., Fekete, B., and Cripe, D., Earth observations for global water security. Curr. Opin. Environ. Sustain., 2013, 5, 633-643.

2. Ghosh, S., Thakur, P. K., Sharma, R., et al., The Potential Applications of Satellite Altimetry with SARAL/AltiKa for Indian Inland Waters. Proc. Natl. Acad. Sci. India Sect. A Phys. Sci., 2017, 87, 661-677.

3. Markus, T., Neumann, T., Martino, A., et al., The Ice, Cloud, and land Elevation Satellite-2 (ICESat-2): Science requirements, concept, and implementation. Remote Sens. Environ., 2017, 190, 260-273.

4. Jasinski, M., Stoll, J., Hancock, D., et al., Algorithm Theoretical Basis Document (ATBD) for Along Track Inland Surface Water Data, Release 004. 2021.

5. Sulistioadi, Y. B., Tseng, K.-H., Shum, C. K., et al., Satellite radar altimetry for monitoring small rivers and lakes in Indonesia. Hydrol. Earth Syst. Sci., 2015, 19, 341-359.

6. Kaushik, A., Ghosh, S., Water level Time-series extraction tool for ICESat-2/ ATL13 (WT4I2). 2019, DOI: https://doi.org/10.5281/zenodo.5618378 